\title{
Community-onset bloodstream infection during the 'after hours' is not associated with an increased risk for death
}

\author{
Kevin B Laupland MD MSc FRCPC ${ }^{1}$, Pamela C Kibsey MD FRCPC ${ }^{2}$, John C Galbraith MD FRCPC ${ }^{2}$
}

\begin{abstract}
KB Laupland, PC Kibsey, JC Galbraith. Community-onset bloodstream infection during the 'after hours' is not associated with an increased risk for death. Can J Infect Dis Med Microbiol 2012;23(4):170-172.

BACKGROUND/OBJECTIVE: Patients admitted to hospital during the 'after hours' (weekends and evenings) may be at increased risk for adverse outcome. The objective of the present study was to assess whether community-onset bloodstream infections presenting in the after hours are associated with death.

METHODS: All patients in the Victoria area of British Columbia, who had first admissions with community-onset bloodstream infections between 1998 and 2005 were included. The day of admission to hospital, the day and time of culture draw, and all-cause, in-hospital mortality were ascertained.

RESULTS: A total of 2108 patients were studied. Twenty-six per cent of patients were admitted on a weekend. Blood cultures were drawn on a weekend in $27 \%$ of cases and, in $43 \%, 33 \%$, and $25 \%$ of cases, cultures were drawn during the day (08:00 to 17:59), the evening (18:00 to 22:59) and night (23:00 to 07:59), respectively. More than twothirds $(69 \%)$ of index cultures were drawn during the after hours (any time Saturday or Sunday and weekdays 18:00 to 07:59). The overall in-hospital case fatality rate was $13 \%$. No difference in mortality was observed in relation to the day of the week of admission or time period of sampling. After-hours sampling was not associated with mortality in a multivariable logistic regression model examining factors associated with death.
\end{abstract}

CONCLUSION: Presentation with community-onset, bloodstream infection during the after hours does not increase the risk of death.

Key Words: Bacteremia; Bloodstream infection; Mortality; Weekend

\section{Une bactériémie d'origine non nosocomiale «après les heures de travail » ne s'associe pas à un risque accru de décès}

HISTORIQUE et OBJECTIF : Les patients hospitalisés « après les heures de travail » (soir et fin de semaine) sont peut-être plus vulnérables aux issues indésirables. La présente étude visait à évaluer si les cas de bactériémie d'origine non nosocomiale qui se présentent après les heures de travail s'associent à des décès.

MÉTHODOLOGIE : Tous les patients de la région de Victoria, en Colombie-Britannique, qui avaient été hospitalisés pour la première fois en raison d'une bactériémie d'origine non nosocomiale entre 1998 et 2005 ont participé à l'étude. Les chercheurs ont déterminé le jour de l'hospitalisation, le jour et l'heure du prélèvement de culture et la mortalité toutes causes confondues en milieu hospitalier.

RÉSULTATS : Au total, 2108 patients étaient à l'étude. Vingt-six pour cent ont été hospitalisés pendant la fin de semaine. Des cultures sanguines ont été prélevées la fin de semaine dans $27 \%$ des cas, et dans $43 \%$, $33 \%$ et $25 \%$ des cas, elles l'ont été pendant la journée (entre 8 h et 17 h 59), le soir ( 18 h à 22 h 59$)$ et la nuit ( 23 h à 7 h 59), respectivement. Plus des deux tiers $(69 \%)$ des cultures de référence avaient été prélevées après les heures de travail (en tout temps le samedi ou le dimanche et la semaine entre $18 \mathrm{~h}$ et $7 \mathrm{~h}$ 59). Le taux cas-décès global en milieu hospitalier s'élevait à $13 \%$. Les chercheurs n'ont observé aucune différence de mortalité selon le jour d'hospitalisation ou la période de l'échantillonnage. D'après le modèle de régression logistique multivariable portant sur les facteurs liés aux décès, les cas après les heures de travail ne s'associaient pas à des décès.

CONCLUSION : Le fait de se présenter avec une bactériémie d'origine non nosocomiale après les heures de travail n'accroît pas le risque de décès. any studies conducted in a number of different medical, surgical I and critically ill populations have indicated that patients admitted to hospitals on weekends and evenings ('after hours') may experience a higher mortality rate (1-9). Many processes of care have been proposed to explain these observations including physician fatigue, lower levels of staffing, restricted availability of tests and procedures, and differences in case-mix, with a potentially higher acuity during these times. We recently reported on a study from the Calgary (Alberta) area that did not find any significant increased risk of death associated with admission with community-onset bloodstream infection during the after hours (10). However, this study requires confirmation in other populations. The objective of the present study was to assess whether the timing of admission for patients with communityonset, bloodstream infection influenced the risk of death in Victoria, British Columbia, between 1998 and 2005.

\section{Patient population}

METHODS

The Vancouver Island Health Authority (VIHA) is one of five health regions within the province of British Columbia. It administers virtually all publicly funded health care to the more than 750,000 residents of Vancouver Island and an adjacent area of the mainland. The south local health area (SLHA) of VIHA (2005 population 357,768) includes the Greater Victoria area and the surrounding communities of Saanich, Sooke and the Gulf Islands. The SLHA has three main acute care institutions, The Royal Jubilee Hospital (Victoria, British Columbia), The Victoria General Hospital (Victoria) and the Saanich Peninsula Hospital (Sannichton, British Columbia). These institutions provide nearly all of the acute inpatient care for residents of the SLHA, with only patients requiring acute bone marrow or organ transplantation and a few other highly specialized services routinely referred

${ }^{1}$ Departments of Medicine, Critical Care Medicine, Community Health Sciences, and Pathology and Laboratory Medicine, University of Calgary and Alberta Health Services, Calgary, Alberta; ${ }^{2}$ Department of Laboratory Medicine, Vancouver Island Health Authority, Royal Jubilee Hospital, Victoria, British Columbia

Correspondence: Dr John C Galbraith, Department of Laboratory Medicine, Vancouver Island Health Authority, Royal Jubilee Hospital, 1952 Bay Street, Victoria, British Columbia V8R 6V5. Telephone 250-370-8755, fax 250-519-1628, e-mail john.galbraith@viha.ca 


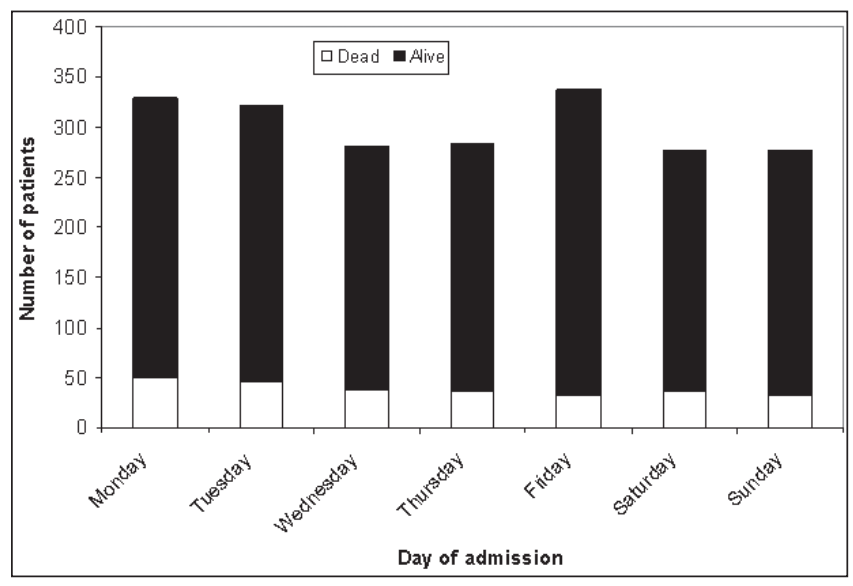

Figure 1) Admission day to Victoria (British Columbia) area hospitals and outcome from community-onset bloodstream infection

to Vancouver (British Columbia). All patients with first admissions to one of the study hospitals with community-onset bloodstream infections during the eight-year period between January 1, 1998 and December 31, 2005 were included. Patients were defined as being SLHA residents based on postal code. The present study was approved by the ethics review board at the VIHA.

\section{Study protocol}

All patients with community-onset bloodstream infections who were admitted to hospital were identified using the regional hospital microbiology laboratory databases (11). Basic demographic, hospital length of stay and in-hospital mortality outcome information was obtained, and patients receiving renal dialysis and active cancer patients were identified from the regional hospital microbiology database. The time of blood culture was defined as the time that the culture was registered in the laboratory system as being drawn. A weekend was a priori defined by the period from 00:00 Saturday to 23:59 Sunday, days as 08:00 to $17: 59$, evening as $18: 00$ to $22: 59$ and nights as $23: 00$ to $07: 59$ (12). Weekday days were defined by days (08:00 to 17:59) from Monday to Friday, and the after hours included all other times (anytime Saturday or Sunday and weekdays 18:00 to 07:59).

\section{Laboratory procedures and definitions}

All blood was cultured using the BACTEC 9240 automated instrument (Becton Dickinson, USA). A blood culture set consisted of an aerobic/ anaerobic lytic bottle pair of BACTEC bottles obtained from a single draw. Organisms were isolated and identified using standard methods. A bloodstream infection was defined as the growth of a pathogenic organism from at least one set of blood cultures. Organisms frequently associated with contamination, including coagulase-negative staphylococci, viridans group streptococci, or Bacillus, Corynebacterium, or Propionibacterium species, were a priori required to have at least two sets of positive blood cultures to be included in the analysis (13). Community-onset bloodstream infections were classified as those obtained from patients that were not admitted to hospital or identified within the first two days of stay in those admitted to an acute care hospital. Infections occurring in the first 28 days of life were also classified as nosocomial and were excluded. Polymicrobial bloodstream infections were those that had more than one incident species coisolated within a two-day period of the index culture draw.

\section{Data management and statistical analysis}

Analysis was performed using Stata version 11.2 (StataCorp, USA). To avoid the assessment of multiple outcomes for a single patient, only the first admission per patient was included in the present study. Nonnormally distributed variables were reported as medians with interquartile ranges (IQR) and compared using the Mann-Whitney $U$ test. Differences in proportions among categorical data were assessed using

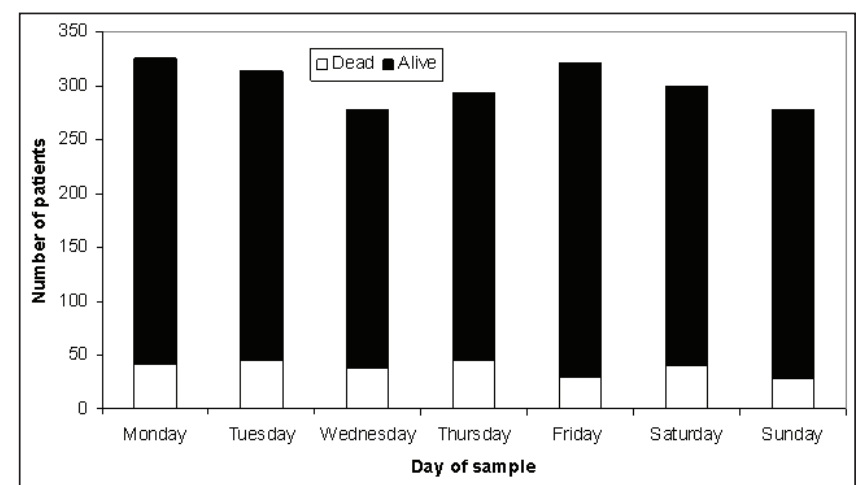

Figure 2) Day of culture draw and outcome for patients with communityonset bloodstream infection admitted to Victoria (British Columbia) area hospitals

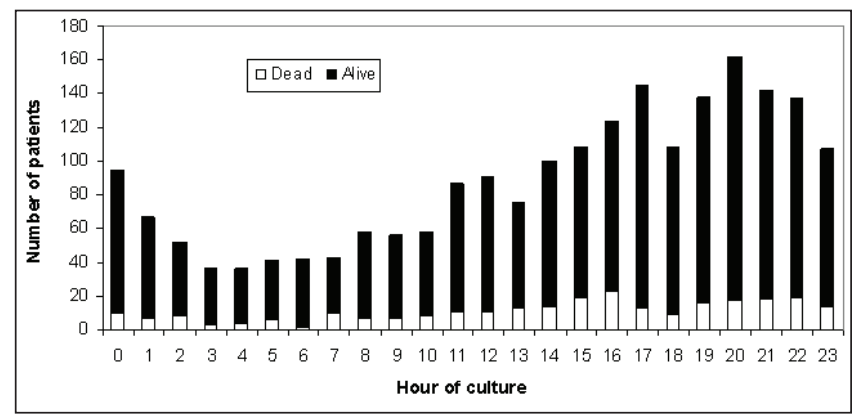

Figure 3) Timing of sampling and outcome of community-onset bloodstream infection for patients with community-onset bloodstream infection admitted to Victoria (British Columbia) area hospitals

Fisher's exact test for pair-wise comparisons and the $\chi^{2}$ test for multiple groups. In all mortality analyses, all-cause in-hospital case fatality was assessed. A multivariable logistic regression model was developed to assess factors associated with mortality. Variables included in the initial model were culture draw during the after hours, age, sex, SLHA residency status, polymicrobial versus monomicrobial infection, and cancer and renal dialysis patients. After hours culture draw was kept in the model and other variables were eliminated $(P>0.1)$ in a backward stepwise fashion to develop the final model. Discrimination was assessed using the area under the ROC curve and calibration using the Hosmer-Lemeshow goodness of fit test.

\section{RESULTS}

During the eight-year study period, a total of 2108 patients had first admissions to study hospitals with community-onset bloodstream infection. Fifty-three per cent $(n=1107)$ of patients were male and the median age was 70.1 (IQR 48.1 to 80.7) years. Twenty-six per cent $(n=554)$ of patients were admitted on a weekend. Blood cultures were obtained on a weekend in 577 (27\%) cases and in 902 (43\%) patients cultures were drawn during 08:00 to $17: 59,687$ (33\%) were drawn during $18: 00$ to $22: 59$ and 519 (25\%) during 23:00 to 07:59. More than two-thirds ( $n=1456$ [69\%]) of index cultures were drawn during the after hours (evenings, nights and/or weekends).

The overall in-hospital case fatality rate was 13\% (269 of 2108). The case-fatality rate was not associated with either the day of admission to hospital ( $\mathrm{P}=0.47$; Figure 1$)$ or the day of sampling $(\mathrm{P}=0.26$; Figure 2$)$. There was no difference in in-hospital case fatality rates between individuals admitted ( 67 of 554 [12\%] versus 202 of 1554 [13\%]; $\mathrm{P}=0.61$ ) or who had cultures drawn (69 of 577 [12\%] versus 200 of 1331 [13\%]; $\mathrm{P}=0.56$ ) on weekends as compared with weekdays. The timing of culture draw varied according to the time of day with a nadir at 03:00 to 04:59 and then a gradual increase until a peak at 20:00 to 20:59 (Figure 3). There was no significant difference $(P=0.33)$ in case fatality depending on whether cultures were drawn during 08:00 to 17:59 (126 of 902 [14\%]), $18: 00$ to $22: 59$ (79 of $687[12 \%]$ ) or $23: 00$ to $07: 59(13 \%)$. 


\begin{tabular}{|c|c|c|c|}
\hline Factor & OR & $95 \% \mathrm{Cl}$ & $\mathbf{P}$ \\
\hline After hours culture & 0.92 & $0.70-1.22$ & 0.563 \\
\hline Cancer patient & 3.03 & $2.01-4.55$ & $<0.001$ \\
\hline Age (per year) & 1.02 & $1.01-1.03$ & $<0.001$ \\
\hline SLHA resident & 0.69 & $0.46-1.04$ & 0.077 \\
\hline Renal patient & 0.45 & $0.18-1.14$ & 0.092 \\
\hline
\end{tabular}

SLHA South Local Health Area

Culture draw during the after hours (weekends and evenings/nights) compared with weekday days did not increase the risk of death. (181 of 1456 [12\%] versus 88 of 652 [14\%]; $\mathrm{P}=0.53$ ).

No significant differences in median age, sex, species or proportion of polymicrobial infections were observed between individuals with cultures drawn during the after hours compared with regular hours. The length of hospital stay was shorter for individuals sampled in the after hours compared with the weekday days (8.5 versus seven days $[\mathrm{P}=0.005])$. The multivariable logistic regression model for factors associated with in-hospital death (area under ROC curve 0.644 [goodness of fit $\mathrm{P}=0.76]$ ) found that, as with the crude analyses, after hours culture was not independently associated with mortality (Table 1).

\section{DISCUSSION}

The present study demonstrated no association between death and presentation with community-onset bloodstream infection during the after hours (weekends, evenings and nights) compared with regular (weekday days) hours. The present study confirms previous findings of a similarly designed study recently conducted in Calgary (10). These studies suggest that the provision of acute care for community-onset infections is consistent during different times of day and days of the week in these centres.

It is not known whether the after hours effect observed in many other studies may be disease or centre specific. While the Calgary and Victoria areas share many common features in, most notably that hospitals are fully publicly funded and that they are in the same country, although in

\section{REFERENCES}

1. Hendry RA. The weekend - a dangerous time to be born? Br J Obstet Gynaecol 1981;88:1200-3.

2. Bell CM, Redelmeier DA. Mortality among patients admitted to hospitals on weekends as compared with weekdays. N Engl J Med 2001;345:663-8.

3. Barnett MJ, Kaboli PJ, Sirio CA, Rosenthal GE. Day of the week of intensive care admission and patient outcomes: A multisite regional evaluation. Med Care 2002;40:530-9.

4. Cram P, Hillis SL, Barnett M, Rosenthal GE. Effects of weekend admission and hospital teaching status on in-hospital mortality. Am J Med 2004;117:151-7.

5. Schilling PL, Campbell DA Jr, Englesbe MJ, Davis MM. A comparison of in-hospital mortality risk conferred by high hospital occupancy, differences in nurse staffing levels, weekend admission, and seasonal influenza. Med Care 2010;48:224-32.

6. Marco J, Barba R, Plaza S, Losa JE, Canora J, Zapatero A. Analysis of the mortality of patients admitted to internal medicine wards over the weekend. Am J Med Qual 2010;25:312-8.

7. James MT, Wald R, Bell CM, et al. Weekend hospital admission, acute kidney injury, and mortality. J Am Soc Nephrol 2010;21:845-51.

8. Aylin P, Yunus A, Bottle A, Majeed A, Bell D. Weekend mortality for emergency admissions. A large, multicentre study. Qual Saf Health Care 2010;19:213-7.

9. Clarke MS, Wills RA, Bowman RV, et al. Exploratory study of the 'weekend effect' for acute medical admissions to public hospitals in Queensland, Australia. Intern Med J 2010;40:777-83. different provinces, there are a number of distinct differences. Victoria is a moderately sized, suburban, coastal city characterized by a large elderly retirement population. Hospitals are predominantly community based with a small number of medical trainees. Calgary is a significantly larger urban city in the prairie region that has the youngest population in Canada. All acute care hospitals in Calgary are teaching facilities with a major presence of medical trainees in many cases. Despite the differences between these two regions, the observations surrounding case-fatality rates and the lack of an after hours effect are remarkably similar.

Where significant after hours effects have been observed in other studies conducted in other regions and with other health-related states, a number of factors have been proposed to explain an after-hours or weekend effect (1-9). The case-mix of patients is an important determinant of outcome and variation during times of the day and days of the week and likely explains, at least in part, the after hours increased mortality effect seen in many studies conducted in other conditions to date (14). Reduced staffing or decreased access to tests and procedures in the after hours and health care worker fatigue and resulting error in the after hours may be contributors $(5,15,16)$. Institutional status as a teaching facility may also play a role (4).

There are a number of potential limitations of the present study that merit discussion. While we included more than 2000 patients, the present study was not powered to exclude very small but potentially statistically significant differences in risk. However, it is notable that the order of effect observed suggests, that if anything, that there may be a reduced risk for death in the after hours (Table 1). Another limitation is that we had limited clinical data on our patients, such that further evaluation of the confounding effects of comorbidity, diagnosis, measures of severity of illness and treatment adequacy could not be included $(14,17)$. Finally, it would be valuable to have specific staffing measures as well as exact times of attendance by the attending services and the actual times of completion of investigations and consults to better explain our observations (5).

In summary, the present study found no association between the timing of presentation during the week or time of day and outcome associated with community-onset bloodstream infections.

DISCLOSURES: No external funding was received in support of the present study. The authors have no conflicts of interest to disclose.

10. Laupland KB. Admission to hospital with community-onset bloodstream infection during the 'after hours' is not associated with an increased risk for death. Scand J Infect Dis 2010;42:862-5.

11. Laupland KB, Schonheyder HC, Kennedy KJ, et al. Rationale for and protocol of a multi-national population-based bacteremia surveillance collaborative. BMC Res Notes 2009;2:146.

12. Laupland KB, Ball CG, Kirkpatrick AW. Hospital mortality among major trauma victims admitted on weekends and evenings: A cohort study. J Trauma Manag Outcomes 2009;3:8.

13. Leal J, Gregson DB, Ross T, Flemons WW, Church DL, Laupland KB. Development of a novel electronic surveillance system for monitoring of bloodstream infections. Infect Control Hosp Epidemiol 2010;31:740-7.

14. Wunsch H, Mapstone J, Brady T, Hanks R, Rowan K. Hospital mortality associated with day and time of admission to intensive care units. Intensive Care Med 2004;30:895-901.

15. Johnson J. The increased incidence of anesthetic adverse events in late afternoon surgeries. Aorn J 2008;88:79-87.

16. Miller AD, Piro CC, Rudisill CN, Bookstaver PB, Bair JD, Bennett CL. Nighttime and weekend medication error rates in an inpatient pediatric population. Ann Pharmacother 2010;44:1739-46.

17. Kumar A, Ellis P, Arabi Y, et al. Initiation of inappropriate antimicrobial therapy results in a fivefold reduction of survival in human septic shock. Chest 2009;136:1237-48. 


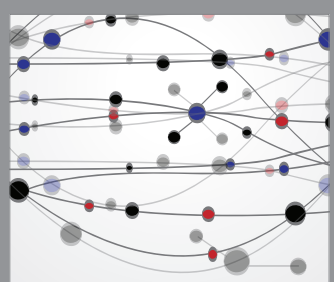

The Scientific World Journal
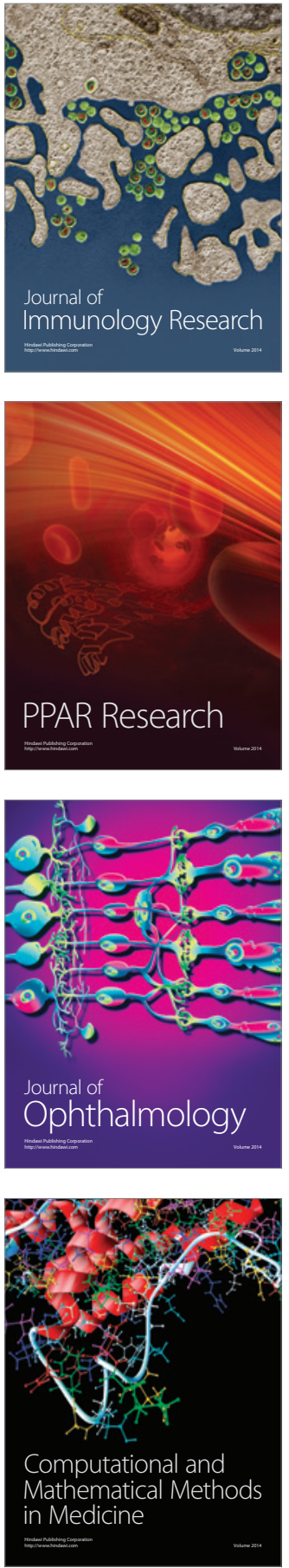

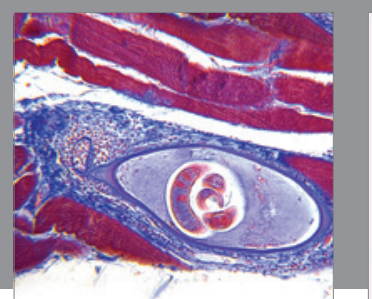

Gastroenterology Research and Practice

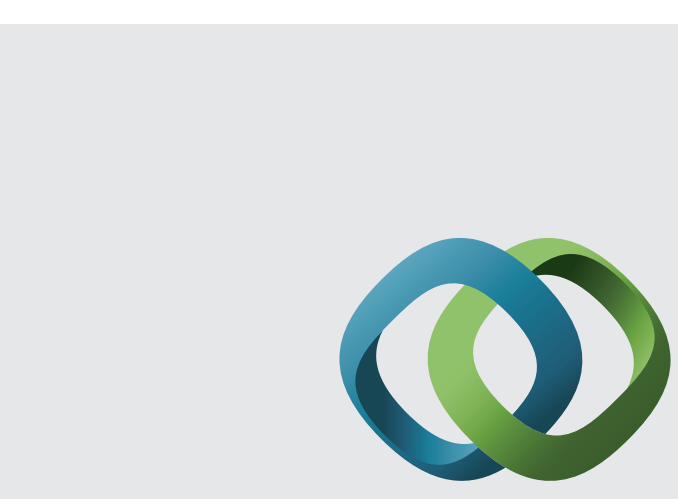

\section{Hindawi}

Submit your manuscripts at

http://www.hindawi.com
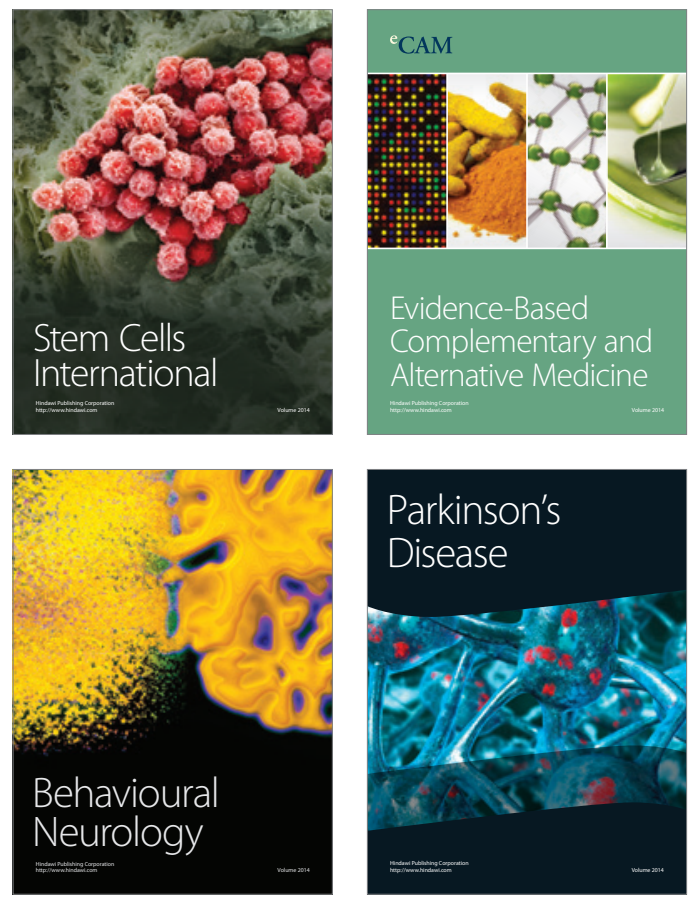
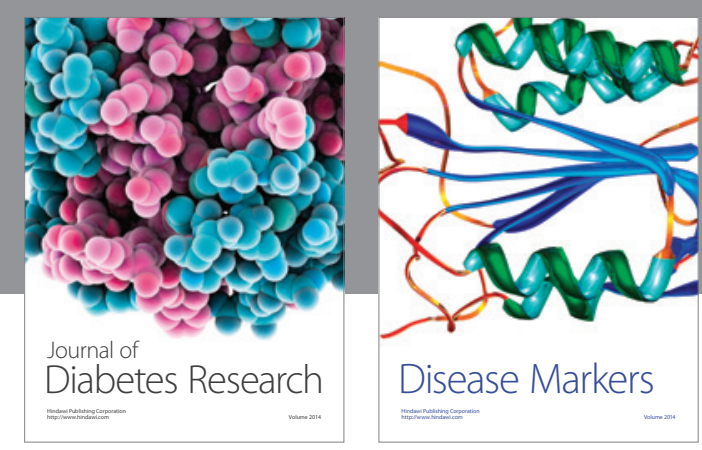

Disease Markers
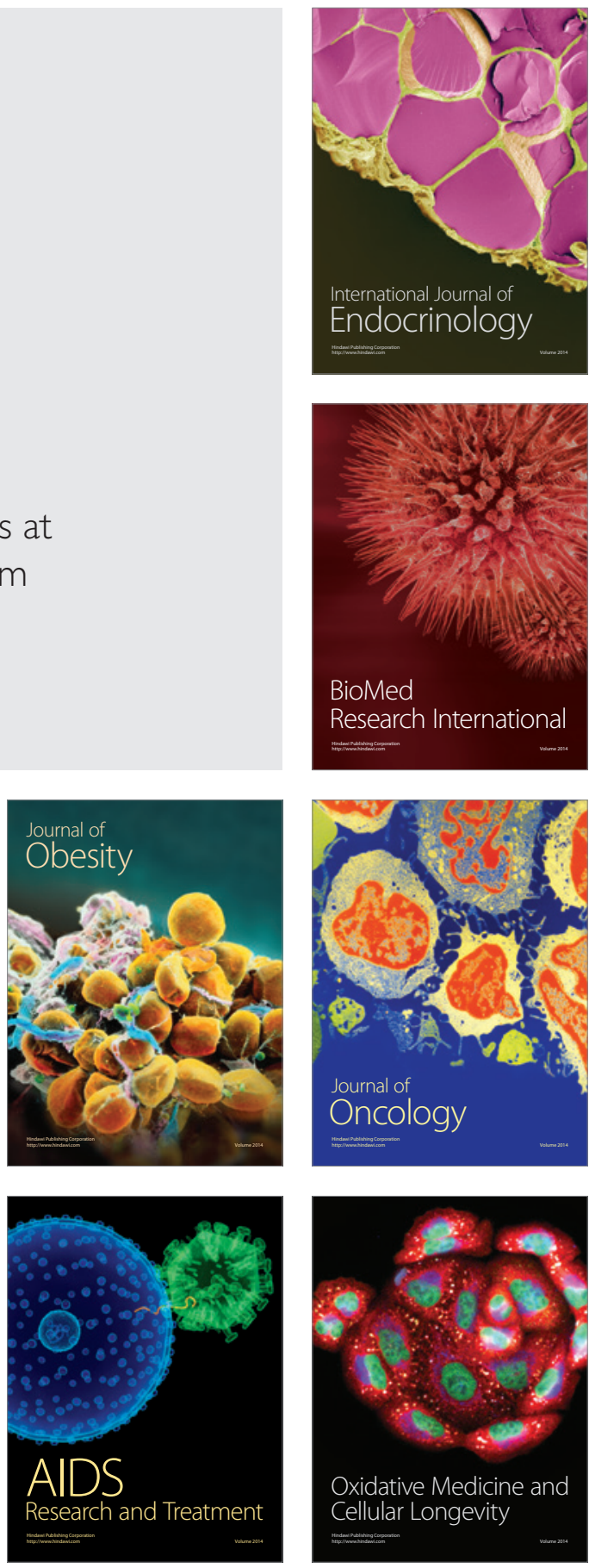